\title{
Olhar o Caminho Percorrido
}

\author{
Look at Way
}

Mirar el Camino Atravesado

Divanise Suruagy Correia ${ }^{1}$

Chegamos ao final de 2016 com mais um número de nossa revista, continuando a trazer temas importantes para a saúde da população.

Apresentamos neste número discussões sobre Políticas Públicas, Assistência na Atenção Básica, Doenças transmissíveis, Humanização e Trânsito, Morte, Sexualidade e Adolescência e Redação de Trabalhos Científicos.

A Atenção Básica atua como a porta de entrada para o Sistema Único de Saúde (SUS) no Brasil e o governo, através do Programa de Valorização da Atenção Básica (PROVAB) busca minimizar o problema de locação de médicos em regiões carentes do Brasil. Essa situação é discutida no artigo aqui publicado, que apresenta a opinião de médicos participantes do PROVAB em Alagoas.

Estudos epidemiológicos vêm mostrando uma transição na prevalência das doenças transmissíveis destacandose as patologias não transmissíveis. Todavia ainda encontramos em nosso país a ocorrência dos dois tipos de agravos, o que se constata com os artigos: Opinião sobre o Trânsito por Profissionais de Saúde e Perfil Epidemiológico dos Co-Infectados pela Neurotoxoplasmose em Portadores da Síndrome da Imunodeficiência Adquirida.

A sexualidade é um componente intrínseco da pessoa e é aspecto fundamental na saúde de adolescentes e jovens, dessa forma ela ultrapassa o lado biológico, e aparece como 
fenômeno psicológico e social, revelando-se através do comportamento humano. No caso dos adolescentes, às vezes, é permeado por situações de risco, como revela o artigo: Aspectos da Vida Sexual de Estudantes Adolescentes.

O estudante de medicina lida com a dor e o sofrimento durante todo o curso, e ao se deparar com a morte, reconhece sua inexperiência em lidar com a situação, apesar da morte ser um evento natural e inevitável da vida humana, é cercada por incertezas e medo de enfrentá-la. Discutir sobre o tema no contexto da graduação em Medicina, poderia transformar-se em um espaço de construção de novos sentidos e novas maneiras de intervenção sobre a realidade, segundo os autores do artigo: Percepções da Morte entre os Estudantes de Medicina, que descrevem a percepção de universitários de medicina sobre a morte e o morrer.

Por sua vez, o ensaio intitulado: Controle Judicial de Políticas Públicas: Princípio da Proporcionalidade como Instrumento da Reserva do Possível, contribui com a temática do controle judicial de políticas públicas numa perspectiva contemporânea e constitucionalmente adequada e possibilita o encontro dos saberes sobre saúde e justiça.

O pré-natal se caracteriza por ser um momento de acompanhamento à mãe e à criança, sendo fundamental o acompanhamento desta dupla, desde o diagnóstico da gravidez na busca de riscos e garantia a uma gestação saudável. Essa atenção deve ser ofertada por uma equipe multiprofissional onde o enfermeiro tem papel essencial no acompanhamento da mulher no ciclo gravídico puerperal e sua atuação pode contribuir com a promoção da saúde das gestantes acolhendo-as desde o início da gravidez. Assim os autores do artigo sobre o tema, trazem a vivencia do estudante de enfermagem na Estratégia de Saúde da Família em município do Estado da Paraíba.

Finalmente, a resenha sobre o Desafio de Redigir um Trabalho Acadêmico, descreve o livro do professor Haroldo Miranda que contribui para o tema, especialmente para aqueles que estreiam no caminho da iniciação cientifica.

Desta forma, este número, ao tempo em que é divulgado no final de 2016, anuncia um novo ano, o de 2017. O tempo atual, além de promover reflexões e avaliações sobre os atos do ano que se encerra, traz expectativas 
sobre o futuro, aparecendo novas esperanças e sonhos.

Neste ano que se encerra conseguimos algumas indexações. Reconhecemos a importância de publicar em periódico qualificado pela Comissão de Aperfeiçoamento de Pessoal do Nível Superior (CAPES) e esperamos que em 2017 obtenhamos nossa qualificação.

Agradecemos aos avaliadores e corpo editorial que acreditaram em nossa proposta e contribuíram com seus conhecimentos no decorrer de 2016. Agradecemos aos autores que compartilharam conosco suas produções, possibilitando a divulgação das mesmas através de nosso periódico.

\section{Desejamos a todos um Feliz Ano} Novo no aguardo de novas colaborações. 